\title{
Prediction and Identification of Antioxidant Peptides in Potato Protein Hydrolysate
}

\author{
Juan Wu $\mathbb{D}^{1,2}$ Chao Mao, ${ }^{1}$ Wenli Zhang, ${ }^{1}$ and Yu Cheng $\mathbb{D}^{1,2}$ \\ ${ }^{1}$ School of Food and Biological Engineering, Jiangsu University, 301 Xuefu Road, Zhenjiang, Jiangsu 212013, China \\ ${ }^{2}$ Institute of Food Physical Processing, Jiangsu University, 301 Xuefu Road, Zhenjiang, Jiangsu 212013, China \\ Correspondence should be addressed to Yu Cheng; chengyu@ujs.edu.cn
}

Received 18 August 2020; Revised 3 September 2020; Accepted 11 September 2020; Published 24 September 2020

Academic Editor: Chunpeng Wan

Copyright (c) 2020 Juan Wu et al. This is an open access article distributed under the Creative Commons Attribution License, which permits unrestricted use, distribution, and reproduction in any medium, provided the original work is properly cited.

Principal component analysis (PCA) was used to cluster the possible amino acid compositions of antioxidant peptides in potato protein hydrolysate $(\mathrm{PPH})$. The antioxidant peptides exhibiting high $\mathrm{ABTS}^{+\bullet}$ scavenging capacity were isolated with the procedure of ultrafiltration, gel filtration, and preparative RP-HPLC and identified by UPLC-MS/MS. Phe, Tyr, and His were shown to group together with $\mathrm{ABTS}^{+\bullet}$ scavenging capacity in component matrix plot. Three prominent peptides, namely, Phe-Tyr, Tyr-Phe-Glu, and Pro-Pro-His-Tyr-Phe, which matched the sequence of patatin and were made up of Phe and Tyr, were identified. The peptide Tyr-Phe-Glu demonstrated antioxidant activity against Caco- 2 cell oxidation induced by $\mathrm{H}_{2} \mathrm{O}_{2}$. The results suggested that multivariate analysis could be used to predict the amino acid compositions of antioxidant peptides.

\section{Introduction}

Enzymatic hydrolysis has been used to improve the solubility of commercial potato protein with low solubility $[1,2]$. The radical scavenging and metal chelating capacity [2] of potato protein hydrolysate ( $\mathrm{PPH})$ have resulted in its potential role in retarding lipid oxidation of food products. It was demonstrated that PPH was able to suppress the lipid oxidation in cooked beef patties [2], cooked frankfurters [3], and food model emulsions [4]. As protein hydrolysates are a mixture of peptides, exploring the exact structure of antioxidant peptides in the potato protein hydrolysate is of interest. That will help to explain their antioxidant mechanisms in food products and contribute to the relationship between structure and activities of peptides.

Waglay and Karboune have identified a lot of peptides from PPH prepared using Flavourzyme and papain [5]. Those peptides matched the sequence in potato protein. However, their bioactivities were not estimated. Besides, few peptide sequences were related to antioxidant peptides. Several antioxidant peptides have been identified in previous research [6-8], while little has been done to predict the amino acid compositions of antioxidant peptides before identification. Bioinformatics methods might be a promising method for predicting the potential sequence of bioactive peptides in potato protein [9-12]. Unfortunately, release of these bioactive peptides from potato protein using proteases was not achieved.

Since antioxidant activity of peptides is related to the composition and sequence of the amino acids, classifying amino acid composition may be able to predict the sequence of the antioxidant peptides. Multivariate analyses such as principal component analysis (PCA) have been used to differentiate and cluster the samples in food science and technology [13-17] and predict the bioactive peptides presented in food proteins [18]. In silico analysis based on the data from databases and literature was used in these studies. Little has been done to use the data collected from experiments.

In our previous research, we have incorporated $\mathrm{PPH}$ fractions with different amino acid compositions into emulsions to retard their lipid oxidation $[6,7]$. We hypothesized that the chemical action of $\mathrm{PPH}$ may be related to antioxidant peptides in these fractions. Furthermore, some special amino acids may make up or contribute a lot to these antioxidant peptides. Therefore, the aim of the present 
research was to predict possible amino acid compositions in antioxidant peptides presented in PPH using PCA through amino acid compositions of those fractions. Then, the individual antioxidant peptides were identified to verify our assumption. The antioxidant capacity of synthesized antioxidant peptide was evaluated by $\mathrm{H}_{2} \mathrm{O}_{2}$ induced cell oxidation model.

\section{Materials and Methods}

2.1. Materials. Potato protein concentrate containing $81 \%$ protein was obtained from AVEBE (Veendam, Netherlands) and used without further purification. Alcalase (endoproteinase from Bacillus licheniformis, 2.4 AU/g), 2,2'-azinobis (3-ethylbenzothiazoline-6-sulfonic acid) (ABTS), 2', $7^{\prime}$ dichlorofluorescein diacetate (DCFH-DA), and Cell Counting Kit-8 were obtained from Sigma-Aldrich Co. (St. Louis, MO, USA). The synthesized peptide YFE (Tyr-PheGlu) with the purity of $98 \%$ was obtained from Top-peptide Bio Co., Ltd. (Pudong, Shanghai, China). Caco-2 human intestinal cell line was purchased from the Cell Bank of the Chinese Academy of Sciences (Shanghai, China). Gibco Dulbecco's modified Eagle's medium (DMEM), fetal bovine serum (FBS), nonessential amino acids (NEAA), penicillin, and streptomycin were purchased from Thermo Fisher Scientific (China) Inc. (Shanghai, China). Malondialdehyde (MDA) assay kit, protein carbonyl assay kit, catalase (CAT) assay kit, glutathione peroxidase (GSH-PX) assay kit, and superoxide dismutase (SOD) assay kit were obtained from Nanjing Jiancheng Bioengineering Institute (Nanjing, China). All of the other analytical-grade chemicals and reagents were obtained from Sinopharm Chemical Reagent Co., Ltd. (Shanghai, China). Distilled and deionized water was used to prepare all the solutions.

2.2. Preparation of $P P H$. $\mathrm{PPH}$ was prepared according to the method of Wang and Xiong [2], and the method description partly reproduces their wording. $\mathrm{PPH}$ was prepared by hydrolyzing potato protein suspension $(40 \mathrm{mg} / \mathrm{mL})$ at $\mathrm{pH}$ 8.0 for $60 \mathrm{~min}$ at $50^{\circ} \mathrm{C}$ using Alcalase with enzyme/substrate ratio of $1 / 100(\mathrm{w} / \mathrm{w})$. After hydrolysis, the $\mathrm{pH}$ of hydrolysate was adjusted to 7.0 with $1 \mathrm{M} \mathrm{NaOH}$, and then the enzyme was inactivated at $80^{\circ} \mathrm{C}$ for $15 \mathrm{~min}$. The hydrolysate was freeze-dried and stored at $4^{\circ} \mathrm{C}$ in sealed plastic bags before use.

2.3. Peptide Fractionation with Different Polarity and Molecular Weight. PPH fractions with different polarity were isolated using ammonium sulfate precipitation as in the method described by Cheng et al. [7]. The fractions precipitated with the ammonium sulfate concentration of $30,50,70$, and $90 \%$ were defined as P30, P50, P70, and P90. In addition, PR was the retentate of $\mathrm{PPH}$ after ammonium sulfate precipitation at the concentration of $90 \%$. The fractions of peak 1 , peak 2 , and peak 3 with different molecular weight were separated from $\mathrm{PPH}$ using gel filtration as in the method described by Cheng et al. [6]. All the fractions were then freeze-dried and stored at $4^{\circ} \mathrm{C}$ in sealed bags before use. The amino acid compositions of these fractions were estimated using OPA derivation method [19].

2.4. Peptide Fractionation Using Ultrafiltration. The PPH solution was passed through Millipore Pellicon-2 ultrafiltration system (Millipore Corporation, Billerica, MA, USA) in the order of 10 and $1 \mathrm{kDa}$ molecular weight cut-off (MWCO) ultrafiltration membranes. The retentate from $10 \mathrm{kDa}$ MWCO ultrafiltration membrane (fraction $>10 \mathrm{kDa}$ ) and $1 \mathrm{kDa}$ MWCO ultrafiltration membrane (fraction in the range of $10-1 \mathrm{kDa}$ ) and the permeate from $1 \mathrm{kDa} \mathrm{MWCO}$ ultrafiltration membrane (fraction $<1 \mathrm{kDa}$ ) were collected and freeze-dried for further use.

2.5. Isolation and Identification of Active Peptides. The method described by Cheng et al. [6] was followed, and the method description partly reproduces their wording. $\mathrm{PPH}$ fraction from $1 \mathrm{kDa}$ MWCO ultrafiltration membrane permeates was isolated using gel filtration (Sephadex G-15), and three fractions were collected. Then the PPH fraction that displayed the highest $\mathrm{ABTS}^{+\bullet}$ scavenging activity within those three fractions was further purified on a SunFire Prep C18 column $(1.9 \times 15 \mathrm{~cm})$ with preparative HPLC (Waters Corporation, Milford, MA). The fractions were eluted using methanol as solvent in linear gradient mode $(10-95 \%$ in $50 \mathrm{~min})$ at the flow rate of $6 \mathrm{~mL} / \mathrm{min}$. The elution fractions were collected at the accuracy of $0.01 \mathrm{~min}$. The procedure was run ten times to get sufficient amounts of peptide fractions. The elution fractions were freeze-dried after removing the methanol.

The purified peptide fractions that displayed the highest $\mathrm{ABTS}^{+}$scavenging activity were then subjected to ultraperformance liquid chromatography (Waters Corporation, Milford, MA), followed by Waters Synapt Mass Quadrupole Time-of-Flight Mass Spectrometer (Waters Corporation, Milford, MA) for sequence identification. Peptide sequencing program in the MassLynx software was used to interpret the spectra. Potato protein sequences published in National Center for Biotechnology Information (NCBI) database were used to match the peptide sequences.

2.6. Radical Scavenging Activity (RSA). The ABTS radical cation $\left(\mathrm{ABTS}^{+\bullet}\right)$ assay was estimated by the method described by Cheng et al. [6]. In addition, the RSA of peptide samples was expressed as Trolox equivalent $(\mu \mathrm{M})$.

2.7. $\mathrm{Fe}^{2+}$ Chelating Activity. Ferrous metal ion chelating activity was determined according to the method of Wu et al. [20], and the method description partly reproduces their wording. One milliliter of $\mathrm{FeCl}_{2}(20 \mu \mathrm{M})$ was mixed with $0.5 \mathrm{~mL}$ of PPH fraction, and then $1 \mathrm{~mL}$ of ferrozine $(500 \mu \mathrm{M})$ was added. The absorbance of the mixture was recorded at $562 \mathrm{~nm}\left(A_{\mathrm{s}}\right)$ after $10 \mathrm{~min}$ incubation. Deionized water was used as the control to determine the absorbance of the mixture $\left(A_{0}\right)$. The $\mathrm{Fe}^{2+}$ chelating activity was calculated as $\left[\left(A_{0}-A_{\mathrm{s}}\right) / A_{0}\right] \times 100 \%$. 
2.8. Cell Culture. Caco- 2 cells $\left(1 \times 10^{5}\right.$ cells $\left./ \mathrm{mL}\right)$ were cultured in high glucose DMEM with $10 \%$ FBS, $1 \%$ NEAA, and 50 units $/ \mathrm{mL}$ of penicillin-streptomycin and incubated in 5\% $\mathrm{CO}_{2}$ at $37^{\circ} \mathrm{C}$. Cell passage numbers $20-50$ were used in the experiments. The cells were grown in a flask for 6 days with fresh medium replaced every other day.

2.9. Induction of Oxidative Stress. The oxidative stress was induced to confluent cells by adding $0.75 \mathrm{mM} \mathrm{H}_{2} \mathrm{O}_{2}$. The Caco-2 cell was inoculated into 96-well culture plates at a concentration of $4 \times 10^{3}-6 \times 10^{3}$ per well and cultured for $24 \mathrm{~h}$. The cells were then incubated for $4 \mathrm{~h}$ with various concentrations of YFE $(0.25-5 \mathrm{mg} / \mathrm{mL})$. Cells were washed twice with PBS, followed by the addition of $0.75 \mathrm{mM} \mathrm{H}_{2} \mathrm{O}_{2}$ for $4 \mathrm{~h}$. At the end of $8 \mathrm{~h}$, the cell viability was determined using Cell Counting Kit-8. Each plate tested included negative control (NEG, treated with treatment medium only) and positive control (POS, treated with treatment medium and $\mathrm{H}_{2} \mathrm{O}_{2}$ ).

2.10. Determination of Lipid Peroxidation and Protein Carbonyl Groups of Caco-2 Cell. The cellular MDA and the protein carbonyl groups were measured to determine the extent of lipid peroxidation and protein oxidation under oxidative stress induced by $\mathrm{H}_{2} \mathrm{O}_{2}$, respectively. MDA and protein carbonyl were determined using kit according to the manufacturer's instructions.

2.11. Activity Determination of Antioxidant Enzyme. CAT, GSH-PX, and SOD activities were determined using kit according to the manufacturer's instructions.

2.12. Statistical Analysis. All assays were carried out in at least three different trials, and data were subjected to analysis of variance (ANOVA). When treatment effects were found significant $(p<0.05)$, the difference between means was identified by Tukey's test. Amino acid compositions and ABTS radial scavenging capacity of $\mathrm{PPH}$ fractions with different molecular weight and polarity were used for principal component analysis (PCA). PCA was performed by SPSS 17.0 (SPSS Inc., Chicago, IL).

\section{Results and Discussion}

3.1. Principal Component Analysis. In our previous research, three fractions (peak 1, peak 2, and peak 3 ) were separated from PPH using Sephadex G-15 gel filtration [6], and five fractions were separated from $\mathrm{PPH}$ using ammonium sulfate precipitation [7]. These fractions were shown to retard lipid oxidation of emulsions. That might be related to their free radical scavenging capacity. Although some antioxidant peptides were identified from these fractions, whether it was possible to predict the sequence of antioxidant peptides by amino acid composition was not clear. In many studies, amino acid composition has been used to assess antioxidant capacity of protein hydrolysates. However, little has been done to use amino acid compositions to predict sequence of antioxidant peptides. To distinguish the effective antioxidant amino acids and predict the antioxidant peptide compositions in $\mathrm{PPH}$, the association of amino acid compositions in those fractions (Table S1) was assessed using principal component analysis (PCA) method. As a result, four components with a cumulative variance of $93.0 \%$ were extracted by PCA (Figure S1). The variance of PC1, PC2, PC3, and PC4 was $47.2 \%, 20.3 \%, 16.6 \%$, and $8.9 \%$, respectively. The first two principal components, which were able to explain about $70 \%$ of data variance, were used to analyze potential amino acid components of antioxidant peptides in $\mathrm{PPH}$. The component matrix plot of $\mathrm{PC} 1$ and PC2 is shown in Figure 1(a). The result showed that the amino acids in different $\mathrm{PPH}$ fractions were able to separate into several groups. Within these groups, three amino acids, namely, Phe, Tyr, and His, were found to be close to ABTS.

Actually, Phe, Tyr, and His have proved to be important components of antioxidant peptides from different protein hydrolysates [21, 22]. A novel peptide, Pro-Phe-His-Pro-Tyr, which was made up of Phe, Tyr, and His was identified from nest protein hydrolysate [23]. It was suggested that some of the antioxidant peptides in PPH might contain at least one of these three amino acids. Fortunately, Iwe have identified several antioxidant peptides existing in potato protein in our previous works [6,7], in which Tyr was common amino acid. However, little was known about the existence of antioxidant peptides which were made up of or based on two or three amino acids from Phe, Tyr, and His, such as Tyr-Phe, PheTyr, and His-Tyr-Phe. To make our hypothesis reasonable, we matched the supposed peptide sequences to the sequence of patatin which was the most abundant protein in potato. The result in Figure 1(b) showed that the peptide sequence of YF, FY, YY, FF, FYF, and HYF (bold) was displayed in the amino acid sequence of patatin. To verify the possible existence of peptides, we carried out the common procedure to identify the antioxidant peptides in PPH in the following sections.

3.2. Ultrafiltration and Gel Filtration Fractionation. PPH was first fractionated using ultrafiltration with cut-off molecular weight of 10 and $1 \mathrm{kDa}$. The $\mathrm{ABTS}^{+\cdot}$ scavenging activity and $\mathrm{Fe}^{2+}$ chelating activity of fractions at the protein concentration of $1 \mathrm{mg} / \mathrm{mL}$ are shown in Figure 2. The fraction with the molecular weight less than $1 \mathrm{kDa}$ indicated the highest $\mathrm{ABTS}^{+\cdot}$ scavenging activity and $\mathrm{Fe}^{2+}$ chelating activity. Therefore, the fraction with the molecular weight less than $1 \mathrm{kDa}$ was loaded into gel filtration unit. G15 was used to separate the PPH less than $1 \mathrm{kDa}$, and three fractions (peak 1 , peak 2 , peak 3 ) were collected. The fraction peak 3 which had the lowest molecular weight exhibited the highest ABTS $^{+\cdot}$ scavenging activity and $\mathrm{Fe}^{2+}$ chelating activity (Figure 3). ABTS $^{+\cdot}$ scavenging activity of peak $3(1 \mathrm{mg} / \mathrm{mL})$ increased by $92.4 \%, 95.4 \%$, and $124.8 \%$ when compared with PPH $(1 \mathrm{mg} / \mathrm{mL})$, BHA $(0.1 \mathrm{mg} / \mathrm{mL})$, and $\mathrm{Vc}(0.05 \mathrm{mg} / \mathrm{mL})$, respectively. Meanwhile, $\mathrm{Fe}^{2+}$ chelating activity of fraction peak $3(1 \mathrm{mg} / \mathrm{mL})$ increased by 6.4 and 3.0 times when compared with PPH $(1 \mathrm{mg} / \mathrm{mL})$ and EDTA $(1 \mathrm{mg} / \mathrm{mL})$, respectively. The results showed that LMW fractions 


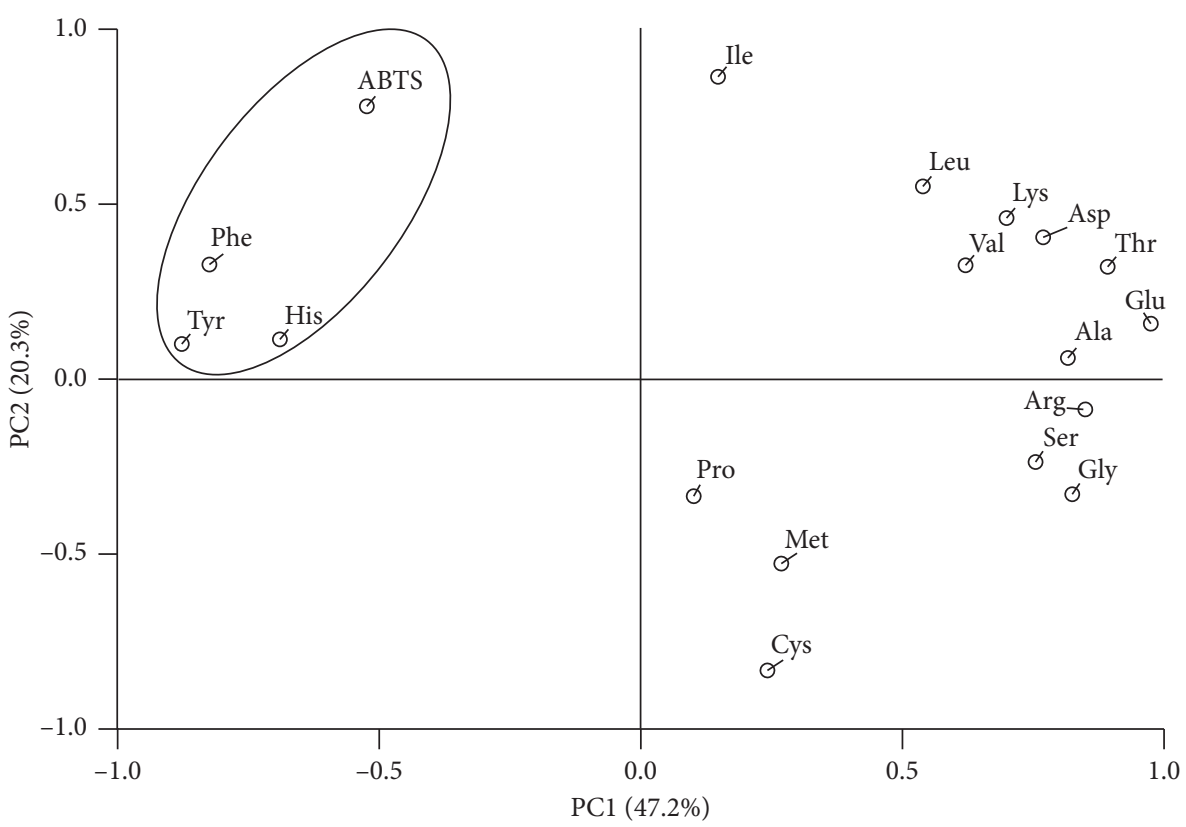

(a)
1 mattnsftil ifmilattss tfatlgemvt vlsidgggik giipatilef legqlqevdn
61 ntdarladyf dviggtstgg lltamittpn etnrpfaaak divpfyfehg pkifqssgsi
121 fgpkydgkyl mqvlqeklge trvhqaltev aissfdiktn kpviftksnl akspeldakm
181 ydicystaaa ptffpphyfa tntsngdkye fnlvdgavat vddpallsis vatklaqvdp
241 kfasiksl nykqmlllsl gtgttsefdkty taeetakwgt arwmlviqkm tsaassymtd
301 yylstafqal dsqnnylrvq enaltgttte lddaseanmq llvqvgedll kksvskdnpe
361 tyeealkrfa kllsdrkklr ankasy

(b)

FIgURE 1: Component matrix plot of amino acid compositions in PPH fractions (a) and amino acid sequence of patatin from NCBI (b).

contributed a lot to the free radial scavenging activity and $\mathrm{Fe}^{2+}$ chelating activity of PPH. In this respect, it has been indicated that many antioxidant peptides were small peptides [24-26]. Furthermore, antioxidant peptides identified from PPH were reported to be made up of 2 to 6 amino acids in previous works [6-8].

3.3. Peptide Purification and Sequence Identification. As peak 3 from gel filtration was still a mixture of peptides, it was purified using preparative RP-HPLC. Twenty-three fractions were separated from peak 3 (Figure 4(a)) and labeled from P3-F1 to P3-F23, respectively. According to $\mathrm{ABTS}^{+\cdot}$ scavenging activity (Figure $4(\mathrm{~b})$ ) and peak area of fractions (Figure 4(b)), three fractions, P3-F6, P3-F8, P3-F14, were selected to identify the peptide sequences by UPLC-MS/MS. Ten peptides whose probability of certainty exceeded 95\% were identified. The sequence of these peptides, which were made up of 2 to 5 amino acids with the molecular weight range from 280 to 700 , is exhibited in Table 1. The results confirmed that antioxidant peptides in PPH were LMW short peptides; nevertheless, different fractionation procedures were used.
The peptide sequences identified were then matched to the sequence of patatin in the NCBI database. The existence of Leu-Asp-Ala-Lys, Phe-Tyr, Tyr-Tyr, Tyr-Phe-Glu, and Pro-Pro-His-Tyr-Phe was indicated (Table 1).

Besides the size of peptide, amino acid residues were known as an important factor for the antioxidant activity of protein hydrolysates. Tyr and Phe which were prone to oxidation [27] for their aromatic group were the most abundant amino acids in these peptides. Moreover, His might react with proteins [28] to protect proteins from oxidation. When Pearson's correlation was used to analyze the relation between content of individual amino acid and $\mathrm{ABTS}^{+\cdot}$ scavenging activity, content of Tyr and Phe also displayed significantly positive relationship with $\mathrm{ABTS}^{+}$ scavenging activity $(p<0.05)$. Furthermore, it was interesting that those peptides except Leu-Asp-Ala-Lys fitted well our hypothesis that antioxidant peptides might be made up of or based on two or three amino acids from Phe, Tyr, and His. Some peptides or fragments including FY, YY, YF, and HYF in patatin were successfully predicted and identified. The MS/MS spectra of the prominent peptides including Phe-Tyr, Tyr-Phe-Glu, and Pro-Pro-His-Tyr-Phe are shown in Figure 5. Phe-Tyr which exhibited the highest peak area in 


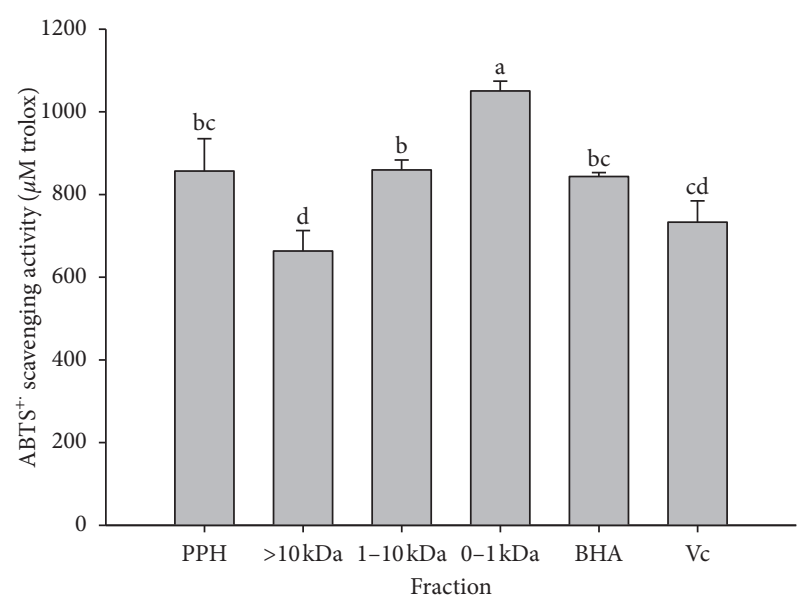

(a)

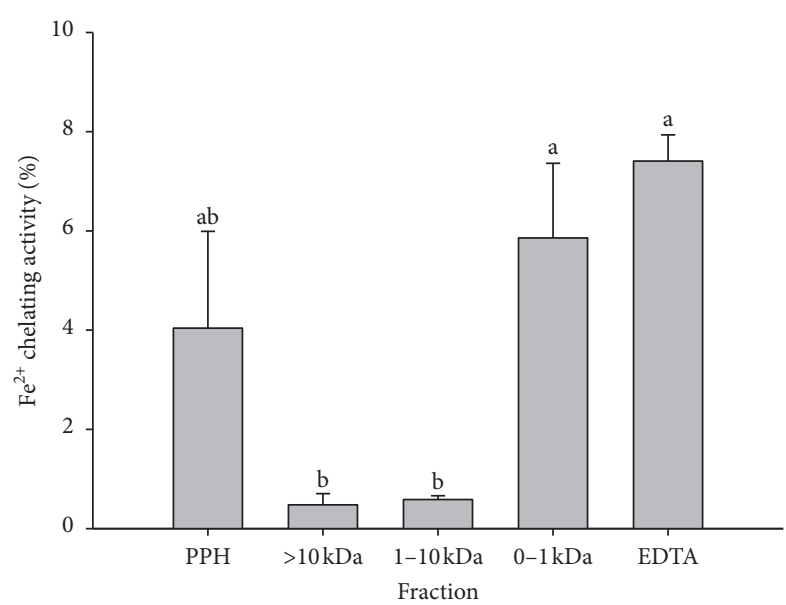

(b)

FIGURE 2: ABTS $^{+\bullet}$ scavenging activity (a) and metal chelating activity (b) of PPH fractions obtained from ultrafiltration using the membrane molecular weight cut-off of 10 and $1 \mathrm{kDa}$ at a protein concentration of $1 \mathrm{mg} / \mathrm{mL}$ (the concentrations of BHA, Vc, and EDTA were $0.1,0.05$, and $1 \mathrm{mg} / \mathrm{mL}$, respectively).

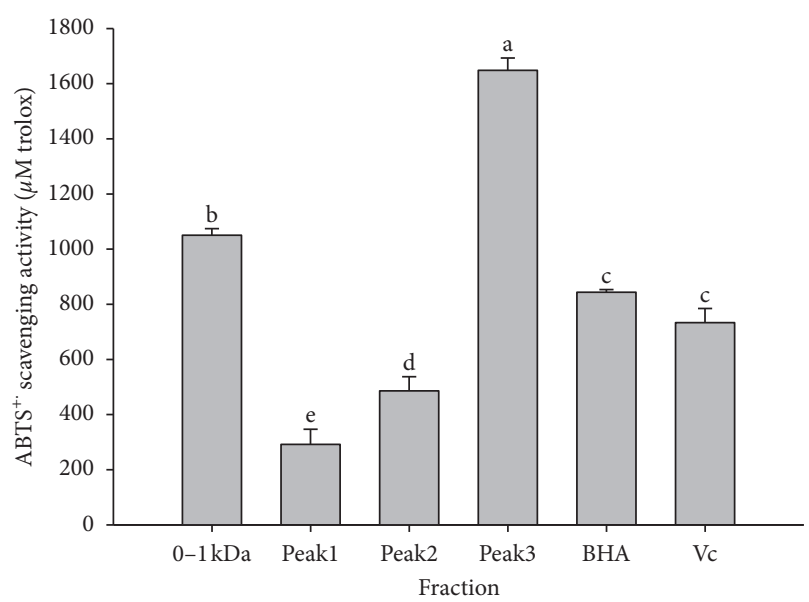

(a)

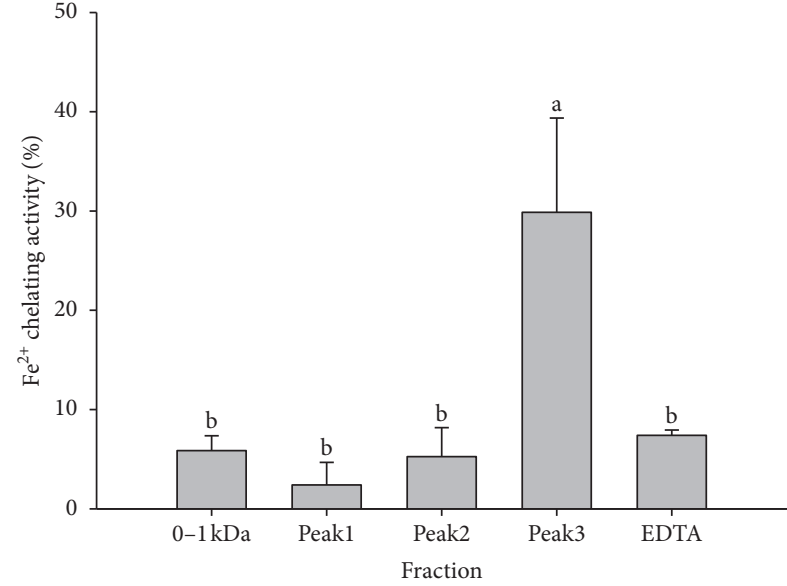

(b)

FIGURE 3: $\mathrm{ABTS}^{+\bullet}$ scavenging activity (a) and metal chelating activity (b) of gel filtration fractions from PPH ultrafiltration fractions passing the membrane with the molecular weight cut-off of $1 \mathrm{kDa}$ at the protein concentration of $1 \mathrm{mg} / \mathrm{mL}$ (the concentrations of BHA, Vc, and EDTA were $0.1,0.05$, and $1 \mathrm{mg} / \mathrm{mL}$, respectively).

chromatography spectrum was the prominent peptide in fraction P3F8. Interestingly, Phe-Tyr was also found in peptide mixture which was separated from the water phase of emulsion prepared using PPH (not published). It seemed that the peptides we identified at the present work were distributed into water phase of emulsions. In our previous work [29], we have identified some antioxidant peptides partitioned at the interface of emulsion, but none of the peptides reported in the present work was the same as them. Our present result could explain the reason why the antioxidant peptides we identified did not match the interfacial peptides. That confirmed our hypothesis in one of the antioxidant mechanisms of $\mathrm{PPH}$ for retarding lipid oxidation of emulsion that $\mathrm{PPH}$ partitioning in the water phase was able to prevent free radical transferring through the oil droplets by their free radical scavenging capacity [4]. In a word, our result showed that PCA might be an efficient method to predict the sequence of antioxidant peptides based on amino acid compositions.

Although Ser-Ser-Glu-Phe in P3F14 did not match the sequence of patatin, it was shown to exist in the sequence of metallocarboxypeptidase inhibitor which was one of the protease inhibitors in potato [30]. Moreover, Ser-Ser-GluPhe is part of the antioxidant peptide Ser-Ser-Glu-Phe-ThrTyr which was identified in the sequence of metallocarboxypeptidase inhibitor [7]. In addition, the remaining part of peptide Thr-Tyr was also identified as antioxidant peptide in PPH [6]. That might be due to the broad cleavage 


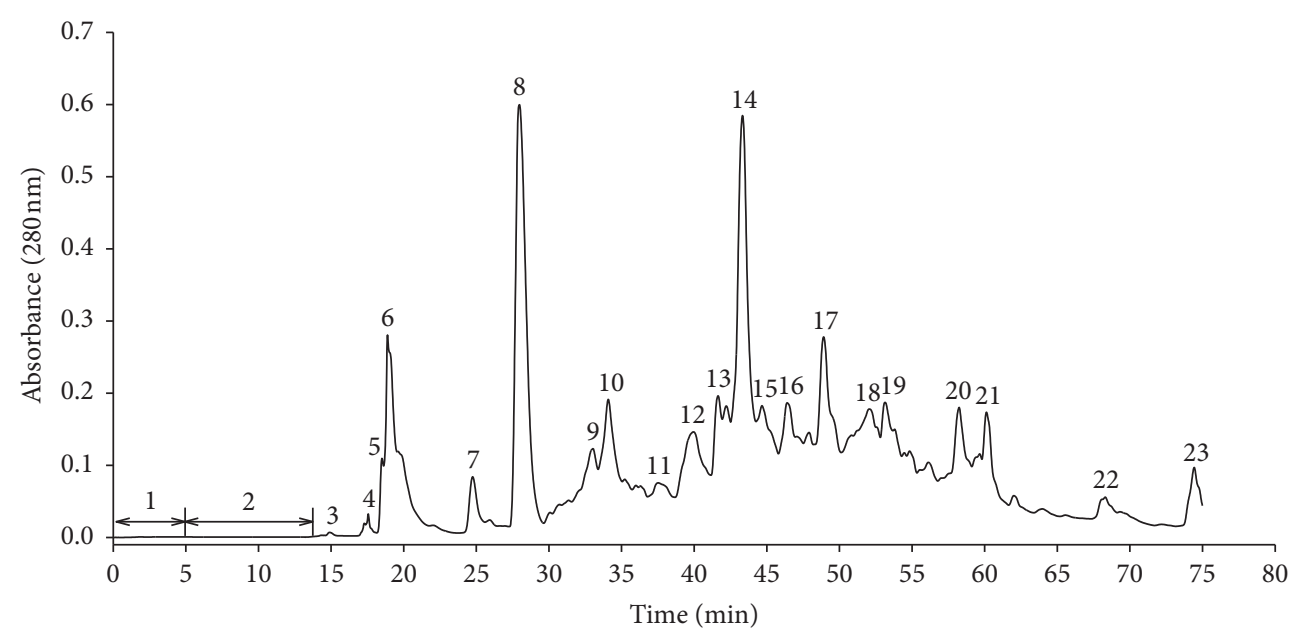

(a)

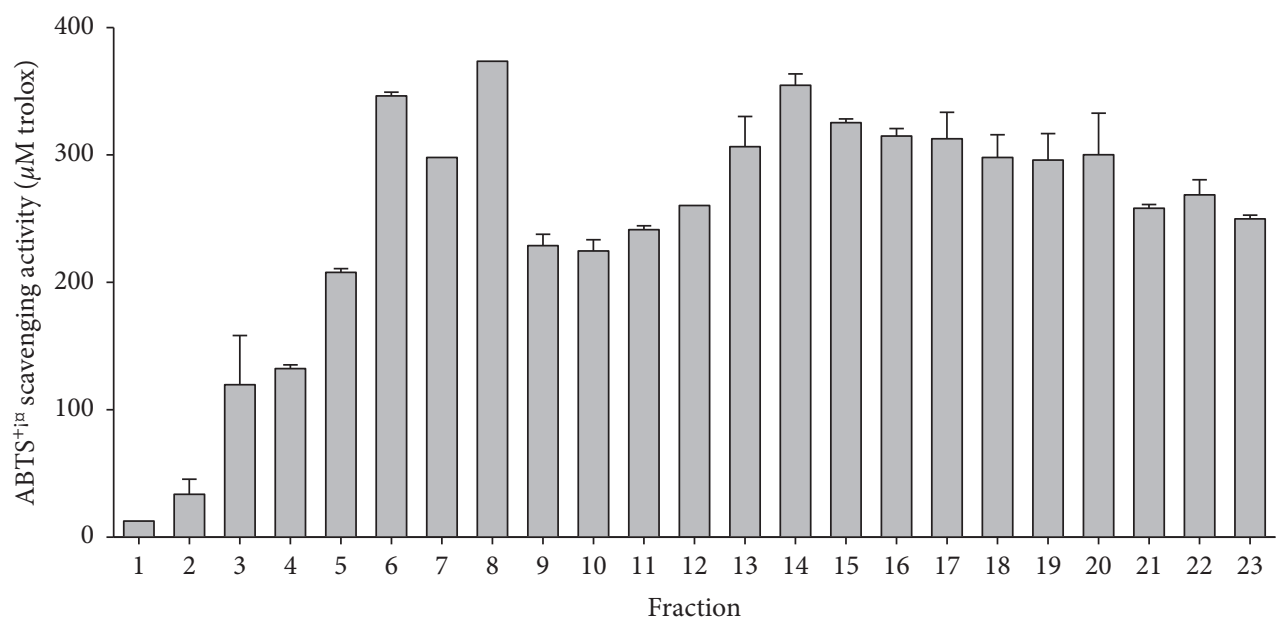

(b)

FIgURE 4: Preparative RP-HPLC spectra of peak 3 obtained from PPH mixture using gel filtration after ultrafiltration with 23 isolated fractions labeled by numbers (a), and ABTS+ scavenging activity of these individual correspondent fractions at the protein concentration of $50 \mu \mathrm{g} / \mathrm{mL}$ (b).

TABLE 1: Antioxidant peptides from selected fractions in PPH that were isolated and identified using UPLC-MS/MS.

\begin{tabular}{lcccc}
\hline Fraction & Peptide & MW & Prob. (\%) & Matched sequence in patatin $^{a}$ \\
\hline \multirow{3}{*}{ P3F6 } & Ala-Ala-His & 297.1 & 99.99 & Not \\
& Leu-Asp-Ala-Lys & 445.3 & 100.00 & f170 akspeldakm \\
& Ser-Ser-Arg-Tyr & 511.2 & 99.70 & Not \\
P3F8 & Phe-Tyr & 328.1 & 100.00 & f101 divpfyfehg \\
& Tyr-Tyr & 344.1 & 100.00 & f301 yylstafqal \\
\hline \multirow{4}{*}{ P3F14 } & Gly-Tyr-Pro-Arg & 491.2 & 99.94 & Not \\
& Ser-Ser-Gly-Phe & 396.2 & 97.99 & Not \\
& Leu-Pro-Thr & 329.2 & 98.80 & Not \\
& Tyr-Phe-Glu & 457.2 & 100.00 & f101 divpfyfehg \\
fro-Pro-His-Tyr-Phe & 659.3 & 99.99 & ptffpphyfa \\
\hline
\end{tabular}

${ }^{a}$ From National Center for Biotechnology Information (NCBI).

site and priority cleavage at the aromatic amino acids of Alcalase [31]. According to the peptides we identified, Alcalase was indicated to hydrolyze the peptide bonds in potato protein on both amine and carboxyl sides of Tyr and Phe; amine side of Ser, Thr, Leu, and Ile; and carboxyl side of
Lys, Glu, Gln, and Met. It was not consisted with the work on casein phosphopeptides released by Alcalase, in which carboxyl side of Glu, Met, Leu, Tyr, Lys, and Gln was the cleavage site [32]. However, the peptides SIDGGGIK (f33f40), TNKPVIF (f159-f167), and SNLAKSPE (f168-f1175) 


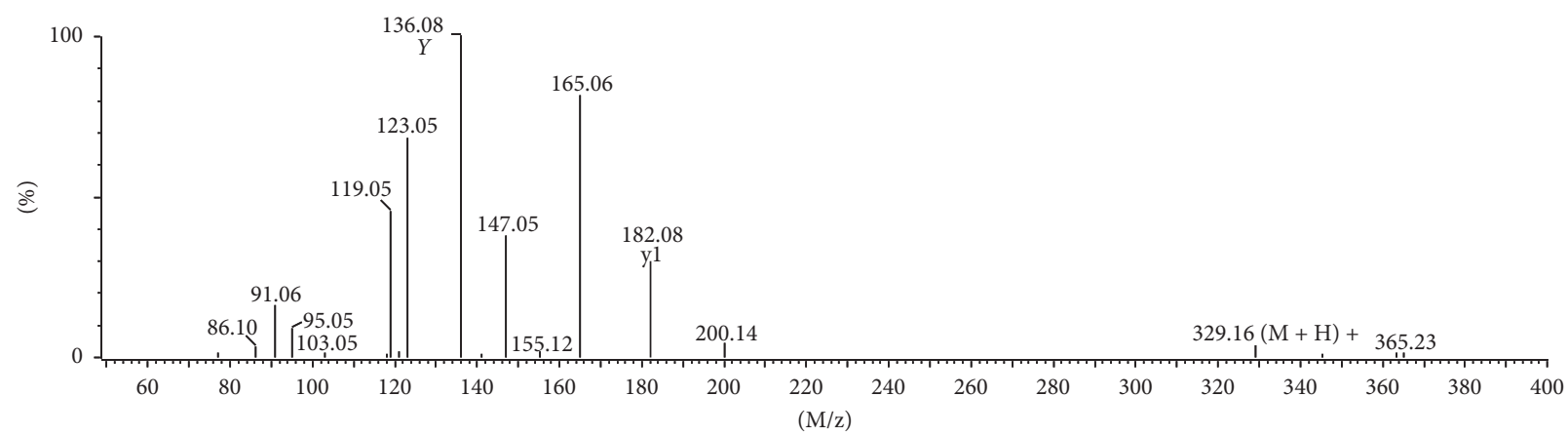

(a)

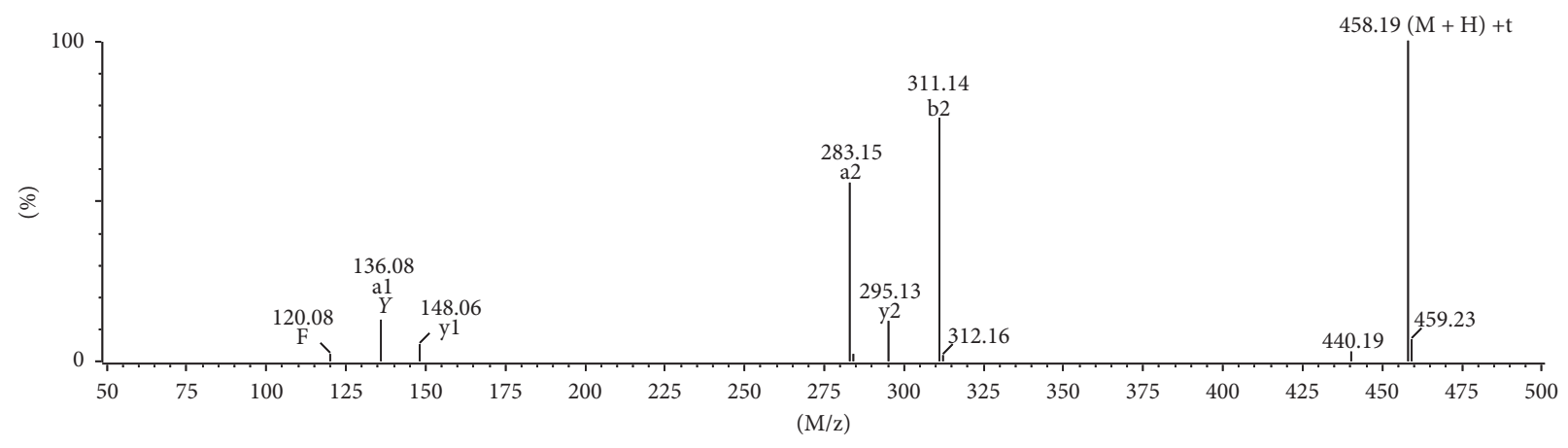

(b)

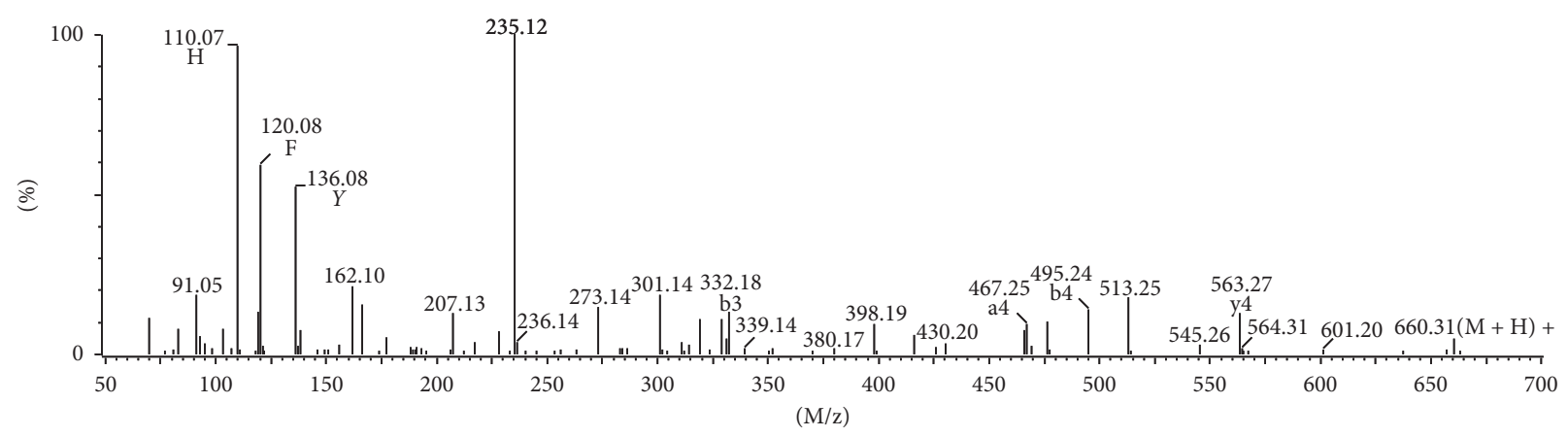

(c)

Figure 5: Tandem mass spectra of prominent peptides present in selected fractions. (a) Phe-Tyr. (b) Tyr-Phe-Glu. (c) Pro-Pro-His-Tyr-Phe.

which were identified by other researchers from PPH prepared using Alcalase [33] demonstrated the cleavage site in carboxyl side of Lys, Glu, and Phe. Although we did not identify the peptides TNKPVIF (f159-f167) and SNLAKSPE (f168-f1175), the antioxidant peptides SFDIK (f153-f158) and LDAK (f176-179) (Table 1) next to these two peptides were identified in our previous [29] and present works, respectively. The existence of Tyr-Phe-Glu in $\mathrm{PPH}$ which has been identified in our previous work [6] was also demonstrated in the present work again. Those results exhibited useful information for PPH's potential application in food industry and showed that enzymatic hydrolysis of potato protein by Alcalase is stable and could be repeated by different producers.

3.4. Effects of YFE on Lipid and Protein Oxidation of Caco-2 Cells. Since YFE was identified as the antioxidant peptide in $\mathrm{PPH}$, the bioactivity of YFE on cellular antioxidation was involved. The cell viability of Caco-2 cells was higher than $85 \%$ when the concentration of YFE was $1 \mathrm{mg} / \mathrm{mL}$. Hence, the YFE concentration of $1 \mathrm{mg} / \mathrm{mL}$ was used for the cellular oxidation trials. The oxidative stress induced by $\mathrm{H}_{2} \mathrm{O}_{2}$ was able to result in oxidation of lipid and protein in cellular membrane. The formation of MDA and carbonyl was used as the biomarker of Caco-2 cell oxidation, as shown in Figure 6.

Normal Caco- 2 cells (NEG group) contained a basal level of MDA and carbonyl due to normal oxidative metabolism. After treating with $0.75 \mathrm{~mm} \mathrm{H}_{2} \mathrm{O}_{2}$ for $4 \mathrm{~h}$, the concentration of MDA and carbonyl groups of POS samples increased by $143 \%$ and $116 \%(p<0.05)$, respectively. Those indicated the oxidative damage on cells. When Caco-2 cells were pretreated with YFE, MDA formation induced by $\mathrm{H}_{2} \mathrm{O}_{2}$ oxidation was reduced by $84.5 \%(p<0.05)$. The formation of carbonyl groups was inhibited, and the concentration of carbonyl group changed a little $(p>0.05)$. The results suggested that YFE was able to suppress cellular oxidation 


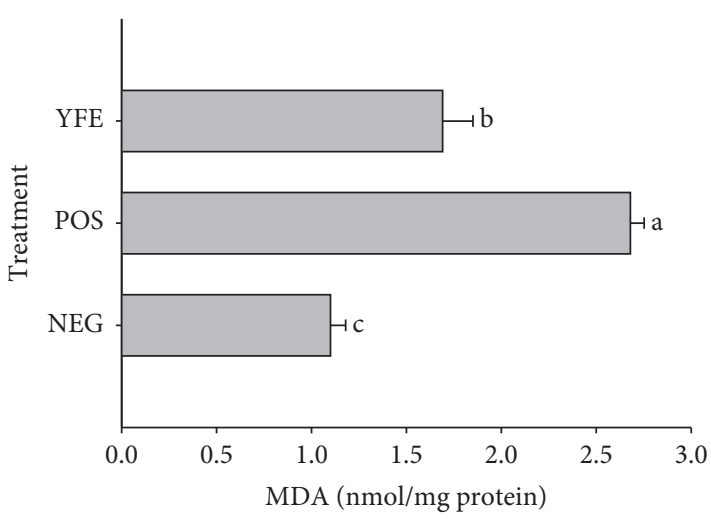

(a)

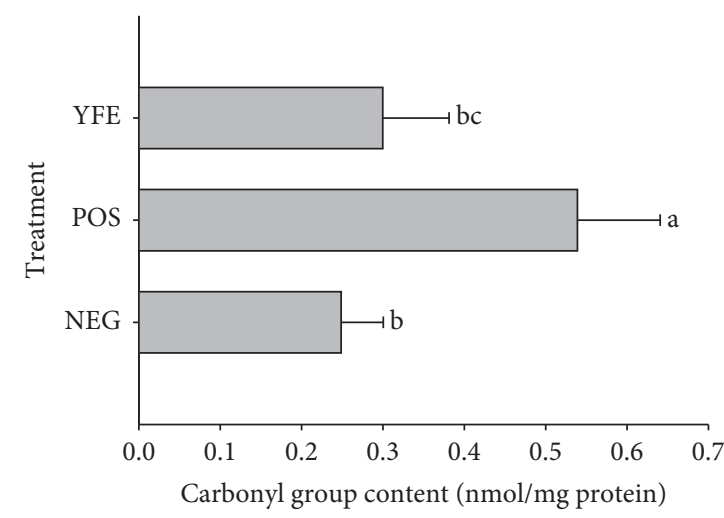

(b)

Figure 6: Effect of YFE pretreatment on lipid (a) and protein oxidation (b) of Caco-2 cells under the oxidation stresses induced by $\mathrm{H}_{2} \mathrm{O}_{2}$.

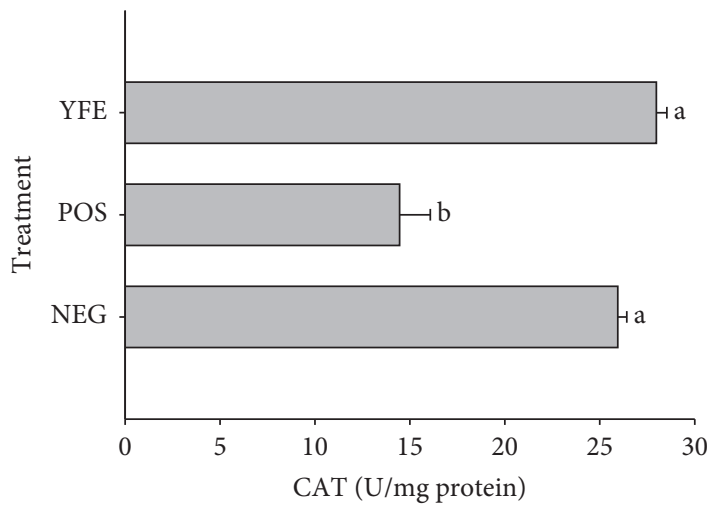

(a)

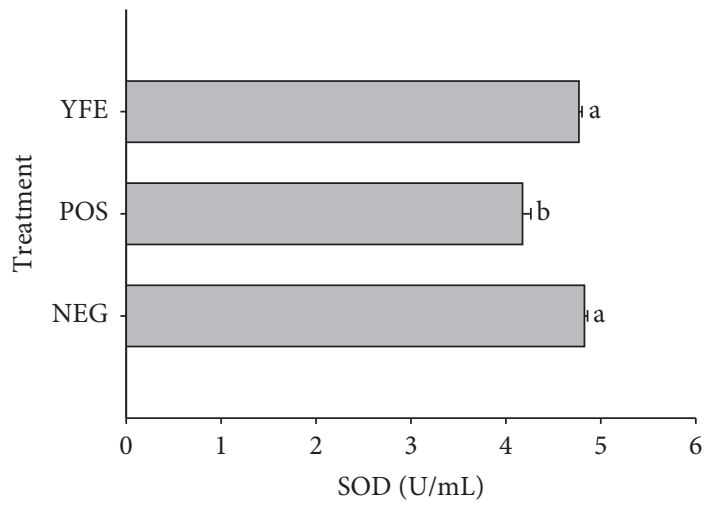

(b)

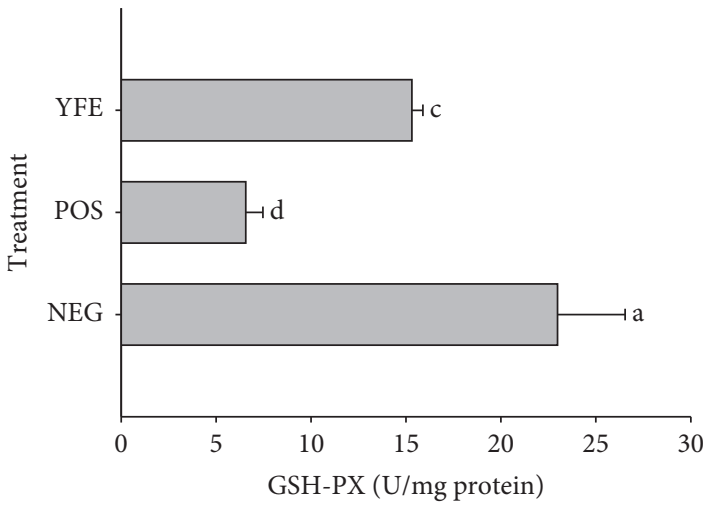

(c)

FIGURE 7: Effect of YFE pretreatment on the activities of antioxidant enzymes CAT (a), SOD (b), and GSH-PX (c) of Caco-2 cells under the oxidation stresses induced by $\mathrm{H}_{2} \mathrm{O}_{2}$.

induced by $\mathrm{H}_{2} \mathrm{O}_{2}$. These protective effects may be due to the radical scavenging activities of YFE or the activation of the cellular defense system against oxidative stress by YFE.

3.5. Effects of YFE on Antioxidant Enzyme Activities. The role of antioxidant enzymes such as CAT, GSH-PX, and SOD in the cellular antioxidant defense system was critical to elucidate the protective effects of YFE against oxidative stress in the cells. Those enzymes can repair cellular oxidation damage induced by free radical through electrontransfer reactions $[34,35]$. The effect of YFE on the activities of CAT, GSH-PX, and SOD of Caco-2 cell is shown in Figure 7. $\mathrm{H}_{2} \mathrm{O}_{2}$ induced oxidation on Caco-2 cells reduced the activities of CAT, GSH-PX, and SOD of Caco-2 cells. Treating the Caco- 2 cells with YFE was able to recover $100 \%$ 
of the CAT and SOD activities and $66.6 \%$ of the GSH-PX activity. The activities of CAT, GSH-PX, and SOD in YFE treated cells increased by $93.5 \%, 133 \%$, and $114 \%(p<0.05)$ when compared with POS samples. Our results were similar to several previous results reporting that antioxidant peptides were able to protect cells against oxidation stresses induced by exogenous oxidants [36-39].

\section{Conclusions}

His, Phe, and Tyr were shown to be related to $\mathrm{ABTS}^{+}$ scavenging activity of PPH by PCA. Some of the antioxidant peptides including Phe-Tyr, Tyr-Tyr, Tyr-Phe-Glu, and ProPro-His-Tyr-Phe which were based on Phe and Tyr were identified by UPLC-MS/MS after fractionation and purification. The results indicated that multivariate analyses like PCA could be used to predict the possible sequence of antioxidant peptides before identification. The antioxidant peptide Tyr-Phe-Glu was able to suppress Caco-2 cellular oxidation induced by $\mathrm{H}_{2} \mathrm{O}_{2}$ through improving the activities of antioxidant enzymes including CAT, GSH-PX, and SOD.

\section{Data Availability}

The data used to support the findings of this study are available from the corresponding author upon request.

\section{Conflicts of Interest}

The authors have no conflicts of interest to declare.

\section{Acknowledgments}

The study was supported, in part, by National Natural Science Foundation of China (Grant no. 31301422), Natural Science Foundation of Jiangsu Province (Grant no. BK20130494), Postgraduate Research and Practice Innovation Program of Jiangsu Province (Grant no. CXLX120672), Senior Personnel Program (Grant no. 11JDG051), and Young Backbone Teachers Program of Jiangsu University.

\section{Supplementary Materials}

Figure S1: cumulative contributing rate of principal component. Table S1: amino acid composition of fractions of $\mathrm{PPH}$ isolated using gel filtration and ammonium sulfate precipitation. (Supplementary Materials)

\section{References}

[1] Y. Cheng, Y. Liu, J. Wu, P. Ofori Donkor, T. Li, and H. Ma, "Improving the enzymolysis efficiency of potato protein by simultaneous dual-frequency energy-gathered ultrasound pretreatment: thermodynamics and kinetics," Ultrasonics Sonochemistry, vol. 37, pp. 351-359, 2017.

[2] L. L. Wang and Y. L. Xiong, "Inhibition of lipid oxidation in cooked beef patties by hydrolyzed potato protein is related to its reducing and radical scavenging ability," Journal of Agricultural and Food Chemistry, vol. 53, no. 23, pp. 9186-9192, 2005.
[3] G. Nieto, M. Castillo, Y. L. Xiong, D. Álvarez, F. A. Payne, and M. D. Garrido, "Antioxidant and emulsifying properties of alcalase-hydrolyzed potato proteins in meat emulsions with different fat concentrations," Meat Science, vol. 83, no. 1, pp. 24-30, 2009.

[4] Y. Cheng, Y. L. Xiong, and J. Chen, "Antioxidant and emulsifying properties of potato protein hydrolysate in soybean oil-in-water emulsions," Food Chemistry, vol. 120, no. 1, pp. 101-108, 2010.

[5] A. Waglay and S. Karboune, "Enzymatic generation of peptides from potato proteins by selected proteases and characterization of their structural properties," Biotechnology Progress, vol. 32, no. 2, pp. 420-429, 2016.

[6] Y. Cheng, J. Chen, and Y. L. Xiong, "Chromatographic separation and tandem MS identification of active peptides in potato protein hydrolysate that inhibit autoxidation of soybean oil-in-water emulsions," Journal of Agricultural and Food Chemistry, vol. 58, no. 15, pp. 8825-8832, 2010.

[7] Y. Cheng, Y. L. Xiong, and J. Chen, "Fractionation, separation, and identification of antioxidative peptides in potato protein hydrolysate that enhance oxidative stability of soybean oil emulsions," Journal of Food Science, vol. 75, no. 9, pp. C760-C765, 2010.

[8] K. Kudo, S. Onodera, Y. Takeda, N. Benkeblia, and N. Shiomi, "Antioxidative activities of some peptides isolated from hydrolyzed potato protein extract," Journal of Functional Foods, vol. 1, no. 2, pp. 170-176, 2009.

[9] Y. Fu, W. Wu, M. Zhu, and Z. Xiao, "In silico assessment of the potential of patatin as a precursor of bioactive peptides," Journal of Food Biochemistry, vol. 40, no. 3, pp. 366-370, 2016.

[10] S. Rajendran, B. Mason, and C. C. Udenigwe, "Peptidomics of peptic digest of selected potato tuber proteins: post-translational modifications and limited cleavage specificity," Journal of Agricultural and Food Chemistry, vol. 64, no. 11, pp. 2432-2437, 2016.

[11] P. J. García-Moreno, S. Gregersen, E. R. Nedamani et al., "Identification of emulsifier potato peptides by bioinformatics: application to omega-3 delivery emulsions and release from potato industry side streams," Scientific Reports, vol. 10 , no. 1 , p. $690,2020$.

[12] P. J. García-Moreno, C. Jacobsen, P. Marcatili et al., "Emulsifying peptides from potato protein predicted by bioinformatics: stabilization of fish oil-in-water emulsions," Food Hydrocolloids, vol. 101, Article ID 105529, 2020.

[13] I. Gregersen, H. Ma, E. A. Alenyorege, and Y. Duan, "In vitro inhibitory effect of tea extracts on starch digestibility," Journal of Food Process Engineering, vol. 42, no. 3, Article ID e13023, 2019.

[14] D. Granato, J. S. Santos, G. B. Escher, B. L. Ferreira, and R. M. Maggio, "Use of principal component analysis (PCA) and hierarchical cluster analysis (HCA) for multivariate association between bioactive compounds and functional properties in foods: a critical perspective," Trends in Food Science \& Technology, vol. 72, pp. 83-90, 2018.

[15] U. Khulal, J. Zhao, W. Hu, and Q. Chen, "Nondestructive quantifying total volatile basic nitrogen (TVB-N) content in chicken using hyperspectral imaging (HSI) technique combined with different data dimension reduction algorithms," Food Chemistry, vol. 197, pp. 1191-1199, 2016.

[16] H. Lin, Z.-x. Man, W.-c. Kang, B.-b. Guan, Q.-s. Chen, and Z.-1. Xue, "A novel colorimetric sensor array based on borondipyrromethene dyes for monitoring the storage time of rice," Food Chemistry, vol. 268, pp. 300-306, 2018. 
[17] J. J. Roberts and D. Cozzolino, "An overview on the application of chemometrics in food science and technology-an approach to quantitative data analysis," Food Analytical Methods, vol. 9, no. 12, pp. 3258-3267, 2016.

[18] A. Iwaniak, P. Minkiewicz, M. Darewicz, M. Protasiewicz, and D. Mogut, "Chemometrics and cheminformatics in the analysis of biologically active peptides from food sources," Journal of Functional Foods, vol. 16, pp. 334-351, 2015.

[19] L. Zhu, J. Chen, X. Tang, and Y. L. Xiong, "Reducing, radical scavenging, and chelation properties of in vitro digests of alcalase-treated zein hydrolysate," Journal of Agricultural and Food Chemistry, vol. 56, no. 8, pp. 2714-2721, 2008.

[20] J. Wu, Y. Cheng, and Y. Dong, "Antioxidant activity of lactobacillus plantarum DY-1 fermented wheat germ extract and its influence on lipid oxidation and texture properties of emulsified sausages," Journal of Food Quality, vol. 2020, Article ID 8885886, 7 pages, 2020.

[21] Q. Liang, X. Ren, H. Ma, S. Li, K. Xu, and A. O. Oladejo, "Effect of low-frequency ultrasonic-assisted enzymolysis on the physicochemical and antioxidant properties of corn protein hydrolysates," Journal of Food Quality, vol. 2017, Article ID 2784146, 10 pages, 2017.

[22] O. Power, P. Jakeman, and R. J. FitzGerald, "Antioxidative peptides: enzymatic production, in vitro and in vivo antioxidant activity and potential applications of milk-derived antioxidative peptides," Amino Acids, vol. 44, no. 3, pp. 797-820, 2013.

[23] M. Ghassem, K. Arihara, S. Mohammadi, N. A. Sani, and A. S. Babji, "Identification of two novel antioxidant peptides from edible bird's nest (Aerodramus fuciphagus) protein hydrolysates," Food \& Function, vol. 8, no. 5, pp. 2046-2052, 2017.

[24] K. Elavarasan and B. A. Shamasundar, "Angiotensin-I-converting enzyme inhibitory activity and antioxidant properties of cryptides derived from natural actomyosin of Catla catla using papain," Journal of Food Quality, vol. 2018, Article ID 9354829, 8 pages, 2018.

[25] R. C. Gao, Y. Shen, W. H. Shu et al., "Optimization of enzymatic conditions of sturgeon muscles and their anti-inflammatory potential," Journal of Food Quality, vol. 2020, Article ID 9698134, 12 pages, 2020.

[26] N. H. Ye, P. Hu, S. L. Xu et al., "Preparation and characterization of antioxidant peptides from carrot seed protein," Journal of Food Quality, vol. 2018, Article ID 8579094, 9 pages, 2018.

[27] E. R. Stadtman and R. L. Levine, "Free radical-mediated oxidation of free amino acids and amino acid residues in proteins," Amino Acids, vol. 25, no. 3-4, pp. 207-218, 2003.

[28] Y. Wang, J. Zhao, W. Zhang, C. Liu, P. Jauregi, and M. Huang, "Modification of heat-induced whey protein gels by basic amino acids," Food Hydrocolloids, vol. 100, Article ID 105397, 2020.

[29] Y. Cheng, J. Chen, and Y. L. Xiong, "Interfacial adsorption of peptides in oil-in-water emulsions costabilized by tween 20 and antioxidative potato peptides," Journal of Agricultural and Food Chemistry, vol. 62, no. 47, pp. 11575-11581, 2014.

[30] L. Pouvreau, H. Gruppen, S. R. Piersma, L. A. M. van den Broek, G. A. van Koningsveld, and A. G. J. Voragen, "Relative abundance and inhibitory distribution of protease inhibitors in potato juice from $\mathrm{cv}$. Elkana," Journal of Agricultural and Food Chemistry, vol. 49, no. 6, pp. 2864-2874, 2001.
[31] O. L. Tavano, "Protein hydrolysis using proteases: an important tool for food biotechnology," Journal of Molecular Catalysis B: Enzymatic, vol. 90, pp. 1-11, 2013.

[32] N. J. Adamson and E. C. Reynolds, "Characterization of casein phosphopeptides prepared using alcalase: determination of enzyme specificity," Enzyme and Microbial Technology, vol. 19, no. 3, pp. 202-207, 1996.

[33] W.-D. Chiang, C.-Y. Huang, C. R. Paul, Z.-Y. Lee, and W.-T. Lin, "Lipolysis stimulating peptides of potato protein hydrolysate effectively suppresses high-fat-diet-induced hepatocyte apoptosis and fibrosis in aging rats," Food \& $\mathrm{Nu}$ trition Research, vol. 60, Article ID 31417, 2016.

[34] S. Wang, R. Mateos, L. Goya, M. Amigo-Benavent, B. Sarriá, and L. Bravo, "A phenolic extract from grape by-products and its main hydroxybenzoic acids protect caco- 2 cells against pro-oxidant induced toxicity," Food and Chemical Toxicology, vol. 88, pp. 65-74, 2016.

[35] Y. Peng, R. Gan, H. Li et al., "Absorption, metabolism, and bioactivity of vitexin: recent advances in understanding the efficacy of an important nutraceutical," Critical Reviews in Food Science and Nutrition, pp. 1-16, 2020.

[36] C. Yang, J. Zhang, Y. Feng, Y. Duan, H. Ma, and H. Zhang, "Purification and identification of novel antioxidant peptides from watermelon seed protein hydrolysates and their cytoprotective effects on $\mathrm{H}_{2} \mathrm{O}_{2}$-induced oxidative stress," Food Chemistry, vol. 327, Article ID 127059, 2020.

[37] C. Wen, J. Zhang, H. Zhang, Y. Duan, and H. Ma, "Effects of divergent ultrasound pretreatment on the structure of watermelon seed protein and the antioxidant activity of its hydrolysates," Food Chemistry, vol. 299, Article ID 125165, 2019.

[38] F. Xu, L. Wang, X. Ju et al., "Transepithelial transport of YWDHNNPQIR and its metabolic fate with cytoprotection against oxidative stress in human intestinal caco-2 cells," Journal of Agricultural and Food Chemistry, vol. 65, no. 10, pp. 2056-2065, 2017.

[39] J. Zhang, J. Zhao, and J. Wu, "Egg ovotransferrin derived IRW exerts protective effect against $\mathrm{H}_{2} \mathrm{O}_{2}$-induced oxidative stress in caco-2 cells," Journal of Functional Foods, vol. 39, pp. 160-167, 2017. 